\section{Commentary: This heart will travel}

\author{
Joseph C. Cleveland, Jr, MD
}

In this issue of the Journal, Ganapathi and colleagues ${ }^{1}$ report on how the change in the heart allocation system has altered transplantation practice. This change in the allocation system was thoughtfully and carefully deliberated by the United Network for Organ Sharing (UNOS). ${ }^{2}$ Indeed, after a lengthy period considering input from all stakeholders, an extensive review of data from the Scientific Registry of Transplant Recipients, and public comment, UNOS changed the allocation policy in 2018 . $^{3}$

As is the case when a very scarce resource-like donor hearts-undergoes a change in allocation, there are divergent opinions regarding whether the change is positive. The least controversial changes included a more standardized definition of cardiogenic shock and tightened time limitations for patients listed at highest status. The most controversial change was to broaden the geographic sharing of donor hearts. This controversy reflects the competing interests of listed patients in each transplantation center. Collectively, as professionals, we should have no argument with the concept of allocating a donor heart to the sickest patient, wherever that patient may be located.

Ganapathi and colleagues used the Scientific Registry of Transplant Recipients database, the gold standard for evaluating waitlist donor and recipient data. They divided the analysis into 2 cohorts, one before the allocation change from 2017 to 2018 and the other after the change from 2018 to 2019. The newer heart allocation system assigns higher status (status 1 or 2) to listed patients with nondischargeable mechanical circulatory support (MCS), venoarterial extracorporeal membrane oxygenation

\footnotetext{
From the Division of Cardiothoracic Surgery, Department of Surgery, University of Colorado Anschutz Medical Center, Aurora, Colo.

Disclosures: The author reported no conflicts of interest.

The Journal policy requires editors and reviewers to disclose conflicts of interest and to decline handling or reviewing manuscripts for which they may have a conflict of interest. The editors and reviewers of this article have no conflicts of interest.

Received for publication March 17, 2021; revisions received March 17, 2021; accepted for publication March 18, 2021; available ahead of print March 24, 2021.

Address for reprints: Joseph C. Cleveland, Jr, MD, Division of Cardiothoracic Surgery, Department of Surgery, University of Colorado Anschutz Medical Center, 12631 East 17th Ave, Building A01, Room 6602, MS C-310, Aurora, CO 80045 (E-mail: joseph.cleveland@ucdenver.edu).

J Thorac Cardiovasc Surg 2023;165:735-6 $0022-5223 / \$ 36.00$

Copyright (c) 2021 Published by Elsevier Inc. on behalf of The American Association for Thoracic Surgery

https://doi.org/10.1016/j.jtcvs.2021.03.066
}

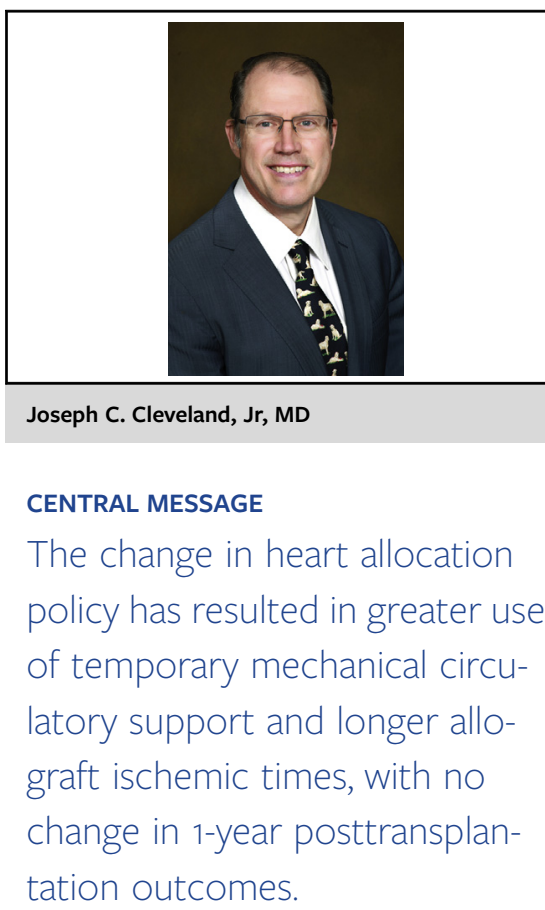

(ECMO), and intra-aortic balloon pumps (IABPs). Of note, implantable, "durable" MCS pumps are now status 4 -with a discretionary 30-day upgrade to status 3. Not surprisingly, the authors' analysis showed a marked increase in the use of nondischargeable MCS, ECMO, and IABPs along with a corresponding decrease in durable left ventricular assist devices as strategies to bridge patients to transplantation. The distance traveled by centers to procure allografts increased by 3 -fold, and ischemic times for the cardiac allograft increased correspondingly. Most reassuring, however, were the findings of no significant change in individual center volume and 1-year posttransplantation survival.

My conclusions based on this analysis can be summarized as follows. First, it is early, and we are just beginning to receive small (nearly 5400 hearts in this analysis) bits of data to analyze the effects of change in heart allocation. Second, the UNOS heart allocation policy actually translates to a greater geographic sharing of organs. This observation is reassuring. Third, the changes in each transplantation center's listing strategies are evident by the transition away from durable MCS to temporary forms of MCS and IABPs. Although the 1-year posttransplantation outcomes from this study appear unchanged, others propose that the increased use of temporary MCS and ECMO may adversely affect 1-year outcomes. ${ }^{4}$ We need long-term follow-up (5- and 10-year data) to ensure that we are not compromising outcomes with the 
greater use of temporary devices as our strategy to bridge our patients to transplantation.

\section{References}

1. Ganapathi AN, Lampert BC, Mokadam NH, Emani S, Hasan AK, Tamer R, et al Allocation changes in heart transplantation: what has really changed? J Thorac Cardiovasc Surg. 2023;165:724-33.e7.
2. Meyer DM, Rogers JG, Edwards LB, Callahan ER, Webber SA, Johnson MR, et al. The future direction of the adult heart allocation system in the United States. Am J Transplant. 2015;15:44-54.

3. US Department of Health and Human Services, Organ Procurement and Transplantation Network. Adult heart allocation. Available at: optn.transplantation. hrsa.gov. Accessed March 16, 2021.

4. Yin MY, Wever-Pinzon O, Mehra MR, Selzman CH, Toll AE, Cherikh WA, et al. Post-transplant outcomes in patients bridged with temporary mechanical circulatory support devices. J Heart Lung Transplant. 2019;38:858-69. 